\title{
GIS-BASED CROP SUPPORT SYSTEM FOR COMMON OAT AND NAKED OAT IN CHINA
}

\author{
Fan Wan ${ }^{1}$, Zhen Wang ${ }^{1}$, Fengmin $\mathrm{Li}^{1}$, Huhua Cao ${ }^{2}$, Guojun Sun ${ }^{1, *}$ \\ ${ }^{1}$ MOE Key Laboratory of Arid and Grassland Ecology, School of Life Science, Lanzhou \\ University, Lanzhou, Gansu Province, P.R. China 730000 \\ ${ }^{2}$ Department of Geography, University of Ottawa, Ottawa, Ontario, Canada K1N $6 N 5$ \\ Corresponding author, Lanzhou 730000, Gansu Province, P.R. China, E-mail: \\ sungj@lzu.edu.cn
}

Abstract: The identification of the suitable areas for common oat (Avena sativa L.) and naked oat (Avena nuda L.) in China using Multi-Criteria Evaluation (MCE) approach based on GIS is presented in the current article. Climate, topography, soil, land use and oat variety databases were created. Relevant criteria, suitability levels and their weights for each factor were defined. Then the criteria maps were obtained and turned into the MCE process, and suitability maps for common oat and naked oat were created. The land use and the suitability maps were crossed to identify the suitable areas for each crop. The results identified $397,720 \mathrm{~km}^{2}$ of suitable areas for common oats of forage purpose distributed in 744 counties in 17 provinces, and $556,232 \mathrm{~km}^{2}$ of suitable areas for naked oats of grain purpose distributed in 779 counties in 19 provinces. This result is in accordance with the distribution of farmingpastoral ecozones located in semi-arid regions of northern China. The mapped areas can help define the working limits and serve as indicative zones for oat in China. The created databases, mapped results, interface of expert system and relevant hardware facilities could construct a complete crop support system for oats.

Keywords: common oat, naked oat, multi-criteria evaluation, GIS; spatial database

Please use the following format when citing this chapter:

Wan, F., Wang, Z., Li, F., Cao, H. and Sun, G., 2009, in IFIP International Federation for Information Processing, Volume 293, Computer and Computing Technologies in Agriculture II, Volume 1, eds. D. Li, Z. Chunjiang, (Boston: Springer), pp. 209-221. 


\section{INTRODUCTION}

Agriculture is the foundation of the national economy in China. Deterioration of ecological environment caused by poor management and unsustainable use of the natural resources has become a serious impediment to agricultural development particularly noticeable in the west of the country. Because of the tolerance to infertile, arid and salt environment, cultivation of common oat (Avena sativa L.) and naked oat (Avena nuda L.) can achieve the harmony and consolidation of production and improvement of the environment (Wang et al., 2006). Besides, common oat and naked oat have high nutritional values (CAMS, 1991; Zhang, 2006) and could be used for both grain and forage purpose. In China naked oat varieties dominate the cultivation of oat, particularly in the semi-arid farming-pastoral areas located northwest and northeast of the country, for the purpose of both grain and forage use. Only in some high-elevation regions in northwest and southwest plant common oat, generally for forage use ( $\mathrm{Li}$ et al., 2007). It has become the main forage cultivated in the pasturing areas in west China to deal with the shortage of forage (Hou, 2003; Xu, 2003).

The identification of the suitable areas is essential to agricultural research and development (Corbett, 1996), it is an introduction for the future cultivation and programming of certain crops. Thus, in this study the suitable areas for common oat and naked oat in China should be identified. These tasks would provide visual guidance for the cultivation and the layout planning of oats in the future.

Suitable areas for crops are determined by evaluation of the climate, soil and topographical characteristics. Many variables and their criteria are involved in the analysis. Geographic information systems (GIS) are best suited for handling spatial data, with due consideration for the spatial variability for an efficient time and cost-effective evaluation (Ahamed et al., 2000). GIS has been applied in crop suitability evaluation in recent years (Gao, 2000). At present, Multi-criteria evaluation (MCE) has received renewed attention within the context of GIS-based decision-making (Pereira and Duckstein, 1993).It could be understood as a world of concepts, approaches, models and methods that aid an evaluation (expressed by weights, values or intensities of preference) according to several criteria. The integration of MCE problems within GIS could give more functionality to the user (Carver, 1991) and could help users to improve decision making processes. This method has been used in searching the best area for an infrastructure (like a plant, a commerce, etc.) and it has been illustrated as a powerful approach to land suitability assessments (Joerin et al., 2001).the application of GIS-based MCE in identify suitable areas for crops or fruit trees in a regional scale has been reported (Ceballos-Silva et al., 2003; Qiu et al., 2005). 
However, the relevant research in identification of suitable areas for a certain crop such as oats in China hasn't been conducted. The objectives of this study were: (1) to establish the national space database of climate, topography and soil; (2) to research the suitable areas of common oat and naked oat within GIS and MCE approach at national scale, provincial scale and county scale in China.

\section{METHODS}

\subsection{Establish of spatial databases}

Climate data was obtained from China Meteorological Administration (CMA). The recorded years were 1970-2002. The variables selected were annual accumulated temperature, maximum temperature, minimum temperature, precipitation and sunlight duration. The climate data were obtained as point data, an interpolation procedure was conducted to estimate the spatial distribution of each climate variable. These works were conducted within the Ordinary Kriging model in the ArcGIS environment. Albers coordinate system was used, the spatial resolution was $1000 \mathrm{~m}$ per pixel. The interpolated maps of accumulated temperature, maximum and minimum temperature were corrected by elevation (Corbett, 1996). First, regression models were carried out using temperature and altitude values from stations to get the temperature lapse rates (TLR) for each of the three factors, and then applied to each pixel of the interpolated temperature maps. The Mean Relative Error (MRE) of before and after adjust by elevation was calculated.

National digital contour map at the scale of 1:250 000 was obtained from the State Bureau of Surveying and Mapping. We use this contour data to create Digital Elevation Model (DEM) within ArcGIS, the process was contours $\rightarrow$ TIN $\rightarrow$ lattice $\rightarrow$ DEM. The slope and elevation information were obtained from the DEM. The Albers coordinate system was used, the spatial resolution was $1000 \mathrm{~m}$ per pixel.

Soil characteristics were taken from digital Soil Type Maps (from ISSCAS) using a scale of 1:1 000000 . Sampling points was created, the total number of points were 99034. The information of soil texture and soil $\mathrm{pH}$ was obtained from soil type. Then the soil texture point data and the soil $\mathrm{pH}$ point data were interpolated into grid maps within ArcGIS. The Albers coordinate system was used and the spatial resolution was $1000 \mathrm{~m}$ per pixel.

Land use information was taken from the digital land use maps of China (from Environmental and ecological Science Data Center for West China, 
2000) at a cell size of $1000 \mathrm{~m}$. The land use type of urban use, residential areas, mining, water bodies and desert were excluded from the analysis as the non-suitable areas for crop cultivation.

\subsection{MCE process for suitable areas of oats}

The first phase of MCE consisted of the establishing of the relevant criteria for the analysis. By means of expert opinion and literatures, it was revealed that Accumulated Temperature, Maximum Temperature, Minimum Temperature, Precipitation, Sunlight Duration, Soil Texture, Soil pH, Elevation and Slope were the relevant factors for common oat and naked oat (Dong et al., 1994). Suitability levels for each of the factors were defined, these levels were used as a base to construct the criteria maps. According to the experts' opinion and the literatures, a specific suitability level per factor for naked oat and common oat were defined (Tables 2 and Table 3). Standardized factor maps were then constructed for common oat and naked oat from the interpolated maps of the factors. Constraint maps including urban use, residential areas, mining, water bodies, and desert were also made. Table 2. Suitability level per factor for common oat

\begin{tabular}{llllll}
\hline \multirow{2}{*}{ Factor } & \multicolumn{5}{c}{ Level of suitability } \\
\cline { 2 - 6 } & Very high & High & Medium & Low & Very low \\
\hline Accumulated & $1400-2700$ & $\begin{array}{l}1000-1400 \\
\text { or } 2700-3500\end{array}$ & $\begin{array}{l}800-1000 \\
\text { or } 3500-4000\end{array}$ & $\begin{array}{l}500-800 \\
\text { or } 4000-4700\end{array}$ & $\begin{array}{l}<500 \\
\text { or }>4700\end{array}$ \\
temperature $\left({ }^{\circ} \mathrm{C}\right)$ & & $400-450$ & $350-400$ & $280-350$ & $<280$ \\
Precipitation $(\mathrm{mm})$ & $450-650$ & or $650-800$ & or $800-1000$ & or $1000-1200$ & or $>1200$ \\
Max Temp $\left({ }^{\circ} \mathrm{C}\right)$ & $14-19$ & $19-21$ or10-14 & $21-23$ or $8-10$ & $23-25$ or $6-8$ & $>25$ or $<6$ \\
Min Temp $\left({ }^{\circ} \mathrm{C}\right)$ & $2-7$ & $-1-2$ or $7-9$ & $-3--1$ or $9-11$ & $11-14$ or-4--3 & $<-4$ or $>14$ \\
Sun duration $(\mathrm{h})$ & $>2400$ & $2100-2400$ & $1900-2100$ & $1700-1900$ & $<1700$ \\
Soil texture & Loam & Sandy loam & Sandy clay loam & Other class & Sand or clay \\
Soil pH & $5.5-6.5$ & $6.5-7.5$ & $7.5-8.5$ & $8.5-9.0$ & $<5.5$ or $>9.0$ \\
Elevation (masl) & $2000-3400$ & $3400-3700$ & $1000-1500$ & $4000-4500$ & $>4500$ \\
Slope $(\%)$ & $0-3$ & $3-8$ & $8-15$ & $15-25$ & $>25$ \\
\hline
\end{tabular}

Table3. Suitability level per factor for naked oat

\begin{tabular}{|c|c|c|c|c|c|}
\hline \multirow{2}{*}{ Factor } & \multicolumn{5}{|c|}{ Level of suitability } \\
\hline & Very high & High & Medium & Low & Very low \\
\hline $\begin{array}{l}\text { Accumulated } \\
\text { temperature }\left({ }^{\circ} \mathrm{C}\right)\end{array}$ & $2400-3500$ & $\begin{array}{l}2000-2400 \\
\text { or } 3500-3900\end{array}$ & $\begin{array}{l}3900-4300 \\
\text { or } 1500-2000\end{array}$ & $\begin{array}{l}1000-1500 \\
\text { or } 4300-4700\end{array}$ & $\begin{array}{l}<1000 \\
\text { or }>4700\end{array}$ \\
\hline Precipitation (mm) & $420-600$ & $\begin{array}{l}350-420 \\
\text { or } 600-750\end{array}$ & $750-1000$ & $250-350$ & $<250$ or $>1000$ \\
\hline $\operatorname{Max} \operatorname{Temp}\left({ }^{\circ} \mathrm{C}\right)$ & $17-20$ & $20-23$ or $14-17$ & $23-25$ or $12-14$ & $25-27$ & $>27$ or $<12$ \\
\hline Min Temp $\left({ }^{\circ} \mathrm{C}\right)$ & $4-7$ & $2-4$ or $7-9$ & $0-2$ or $9-11$ & $-2-0$ or $11-14$ & $<-2$ or $>14$ \\
\hline Sun duration (h) & $>2400$ & $2100-2400$ & $1900-2100$ & $1700-1900$ & $<1700$ \\
\hline Soil texture & Loam & Sandy loam & Sandy clay loam & Other class & Sand or clay \\
\hline Soil pH & $5.5-6.5$ & $6.5-7.5$ & $7.5-8.5$ & $8.5-9.0$ & $<5.5$ or $>9.0$ \\
\hline Elevation (masl) & $1400-2200$ & $\begin{array}{l}1000-1400 \\
\text { or } 2200-2500\end{array}$ & $\begin{array}{l}<1000 \\
\text { or } 2500-2700\end{array}$ & $2700-3000$ & $>3000$ \\
\hline Slope (\%) & $0-3$ & $3-8$ & $8-15$ & $15-25$ & $>25$ \\
\hline
\end{tabular}


Pair-wise comparison matrixes were made to get the weights of each factor for common oat and naked oat. The comparison concerns the relative importance of the two criteria involved in determining the suitability of the stated objective. This method use a scale with values from 1/9 to 9 to rate the relative preferences of the two criteria. In this study, factors were rated according to the opinion of crop experts from the Academy of Agricultural Sciences of Neimenggu and the Dry Farming Research Center of Dingxi.

Once the factors and constraints maps have been obtained, and the weights of each factor were calculated, the next step was to multiply each factor map by its weight and then sum the results. These works were conducted with the Weighted Overlay module in the ArcGIS environment. Next the summed map was overlaid with the Constraint maps to erase the non-suitable areas for crop cultivation, then the suitability map which has values in the same range as the standardized factor maps was produced.

Finally, the land use map and the maps of suitable areas for common oat and naked oat were crossed respectively. In this way, we obtained useful information concerning the spatial distribution of several suitability levels, according to Land use information.

\section{RESULTS}

\subsection{Adjust of interpolated temperature maps by elevation}

For accumulated temperature, the temperature lapse rates (TLR) was $1.12626\left({ }^{\circ} \mathrm{C} / \mathrm{m}^{-1}\right), \mathrm{R}^{2}=0.57$; for maximum temperature, the TLR was 0.0043 $\left({ }^{\circ} \mathrm{C} / \mathrm{m}^{-1}\right), \mathrm{R}^{2}=0.88$; for minimum temperature, the TLR was $0.0036\left({ }^{\circ} \mathrm{C} / \mathrm{m}^{-1}\right)$, $\mathrm{R}^{2}=0.75$. The Mean Relative Error (MRE) between the measured $\left(\mathrm{Z}_{\mathrm{oi}}\right)$ and the simulated value $\left(Z_{e i}\right)$ of before and after adjust by elevation was calculated using the following formula (1) and the results showed in table 5.

$$
M R E=\frac{1}{n} \sum_{i=1}^{n}\left|\frac{Z_{o i}-Z_{e i}}{Z_{o i}}\right|
$$

Table 5. Mean relative errors (MRE) results of before and after adjust

\begin{tabular}{lccc}
\hline & $\begin{array}{c}\text { Maximum } \\
\text { temperature }\end{array}$ & $\begin{array}{l}\text { Minimum } \\
\text { temperature }\end{array}$ & $\begin{array}{c}\text { accumulated } \\
\text { temperature }\end{array}$ \\
\hline Before adjust & 0.0438 & 0.4694 & 0.1160 \\
After adjust & 0.0279 & 0.0502 & 0.0667 \\
\hline
\end{tabular}


According to table 5, the Mean Relative Error of interpolation much decreased after adjusted by elevation. Therefore the adjusted temperature maps were used to obtain the standardized factor maps.

\subsection{MCE process for common oat}

Weights of factors for common oat were calculated based on the Pair-wise comparison matrixes. The most important factors for common oat were: Accumulated Temperature (0.3078), Precipitation (0.2732), and Elevation (0.1441); Minimum Temperature (0.0779), Maximum Temperature (0.0745) and Sunlight Duration (0.0536) followed; Soil pH (0.0263), Soil Texture Class (0.0255) and Slope (0.0171) were the factors with the least importance. The consistency ratio was 0.04 , considered acceptable. Once the standardized factor maps (Fig.1) and the weights per factor were obtained, the MCE was carried out and the map of suitable areas for common oat was obtained, then it was overlaid by the provincial boundaries to facilitate observation of the map (Fig. 2).

According to Fig. 2, Very high suitability areas were located in some mountain areas in Neimenggu, Hebei, Shanxi, Shaanxi, Gansu, Ningxia, Qinghai, Sichuan, Xinjiang and Xizang provinces. These areas generally had enough sunlight, cool weather, and without drought.

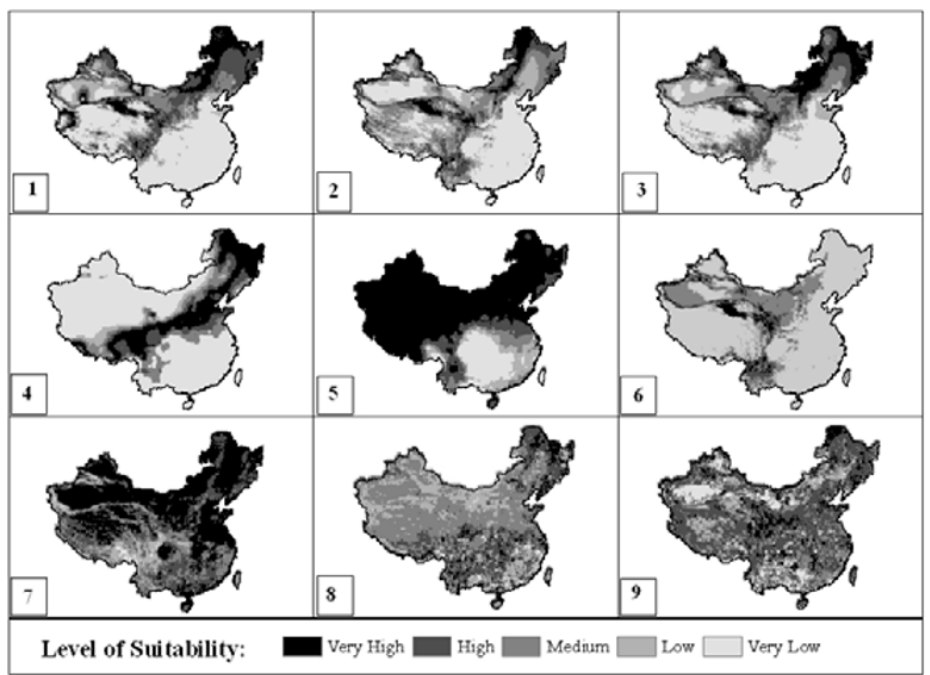

Fig. 1: Factor map for common oat, including suitability levels for each factor. $1=$

Accumulated temperature, $2=$ Maximum temperature, $3=$ minimum temperature, $4=$ Precipitation, $5=$ Sunlight duration, $6=$ Elevation, $7=$ slope, $8=$ Soil $\mathrm{pH}, 9=$ Soil texture class.

The suitability map and the land use map were crossed and the extent of each suitability level per land use class was calculated (Table 6). The result identified 
$19,343 \mathrm{~km}^{2}$ with very high suitability level and $378,377 \mathrm{~km}^{2}$ with high suitability level in Dryland, these areas which totaled $397,720 \mathrm{~km}^{2}$ can be considered as the best areas for common oat cultivation.

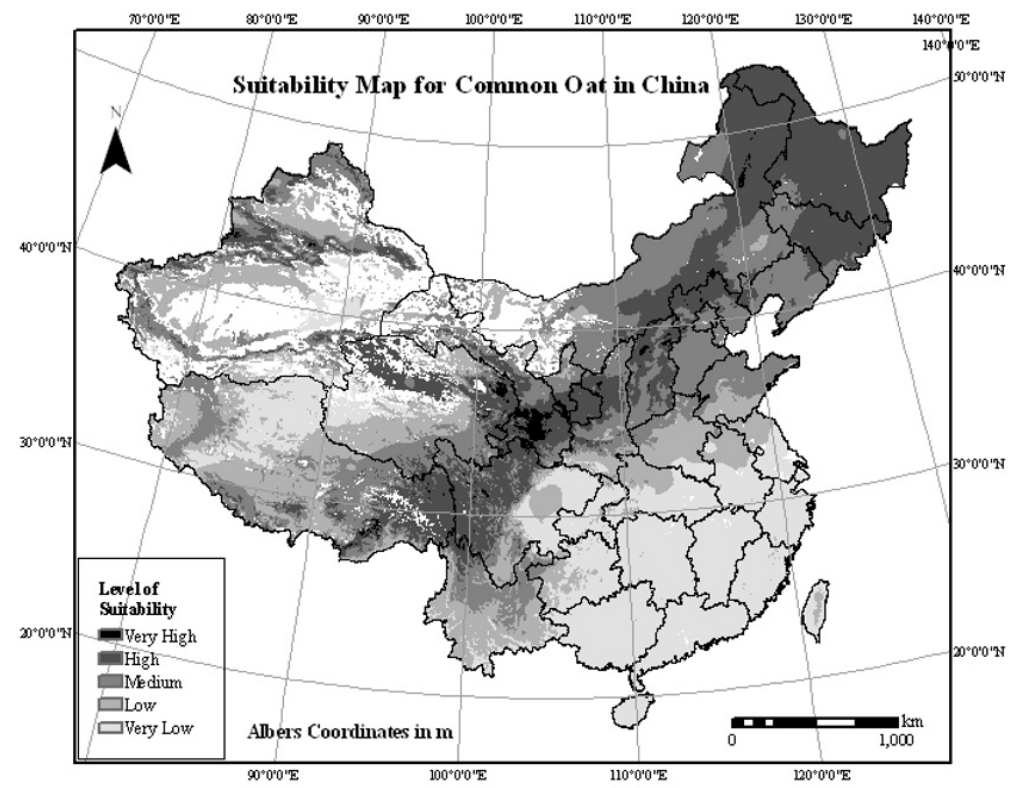

Fig.2: Suitability map for common oat in China.

Table 6. Result of crossing the suitability map for common oat and land use map.

\begin{tabular}{llllll}
\hline \multirow{2}{*}{ Land use } & \multicolumn{5}{c}{ Suitability level } \\
\cline { 2 - 5 } & Very high & High & Medium & Low & Very low \\
\hline Pf & $155^{\text {a }}$ & 19892 & 27180 & 66432 & 353581 \\
$\mathrm{Dl}$ & 19343 & 378377 & 467655 & 326092 & 237441 \\
$\mathrm{Fl}$ & 40811 & 555173 & 188228 & 181954 & 463201 \\
$\mathrm{Sh}$ & 6301 & 91404 & 72728 & 79433 & 137201 \\
$\mathrm{Sp}$ & 4435 & 68990 & 62218 & 80716 & 324528 \\
$\mathrm{Hg}$ & 24255 & 360558 & 478059 & 274141 & 110051 \\
$\mathrm{Mg}$ & 24088 & 328421 & 424708 & 271086 & 143043 \\
$\mathrm{Lg}$ & 6816 & 106017 & 321726 & 213171 & 72589 \\
$\mathrm{Sa}$ & 2 & 30715 & 25871 & 32931 & 17344 \\
$\mathrm{Ml}$ & 309 & 49346 & 17657 & 5677 & 517 \\
$\mathrm{Bl}$ & 0 & 33127 & 24330 & 20485 & 765 \\
\hline
\end{tabular}

${ }^{a}$ Units are in square kilometers $\left(\mathrm{km}^{2}\right) . P f=$ Paddy field, $\mathrm{Dl}=$ Dry land, $\mathrm{Fl}=$ Forest land, $\mathrm{Sh}$

= Shrub land, $\mathrm{Sp}=$ Sparse forest, $\mathrm{Hg}=$ High-coverage grassland, $\mathrm{Mg}=$ Moderate-coverage grassland, $\mathrm{Lg}=$ Low-coverage grassland, $\mathrm{Sa}=$ Saline-alkaline land, $\mathrm{Ml}=$ Marshland, $\mathrm{Bl}=$ Bare land. 
After overlaying the results with the province and county boundaries, suitability maps for common oat in each province and each county were obtained. 744 counties in 17 provinces were identified as potential areas for planting common oat, and their areas were calculated. Suitable areas per land use type for each province were shown in table 7, according to the result, Heilongjiang province has a largest potential area for common oat located in Dry land, Gansu, Jilin and Neimenggu province followed.

Table 7. Suitable areas for common oat in each province, take Gansu, Heilongjiang, Jilin, Neimenggu and Xinjiang province for example.

\begin{tabular}{lccccccccccc}
\hline \multirow{2}{*}{ Province } & \multicolumn{10}{c}{ Land use } \\
\cline { 2 - 12 } & Pf & Dl & Fl & Sh & Sp & Hg & Mg & Lg & Sa & Ml & Bl \\
\hline Gansu & 1 & 58064 & 17977 & 2868 & 3942 & 31659 & 32960 & 23448 & 35 & 494 & 62 \\
Heilongjiang & 10511 & 140498 & 169378 & 8746 & 30151 & 36206 & 5774 & 1702 & 2198 & 23194 & 10 \\
Jilin & 8147 & 52815 & 65839 & 1480 & 6394 & 2880 & 1306 & 262 & 1570 & 2269 & 72 \\
Neimenggu & 403 & 51724 & 138292 & 20227 & 5391 & 111403 & 49708 & 11976 & 1434 & 18344 & 48 \\
Xinjiang & 0 & 2505 & 11703 & 888 & 618 & 59478 & 41516 & 31496 & 53 & 928 & 1180 \\
\hline
\end{tabular}

\subsection{MCE process for naked oat}

For naked oat, the weights of each factor were as follows: Accumulated Temperature (0.3124), Precipitation (0.2827), Minimum Temperature (0.0920), Maximum Temperature (0.0888), Elevation (0.0766), Sunlight Duration (0.0717), Soil pH (0.0289), Soil Texture (0.0285) and Slope (0.0184). The consistency ratio was 0.04 , considered acceptable. Once the standardized factor maps (Fig.3), the constraint maps and the weights per factor were obtained, the MCE was carried out and the maps of suitable areas for naked oat were obtained (Fig. 4).

According to Fig.4, very high suitability areas were located in some areas in Heilongjiang, Neimenggu, Jilin, Hebei, Shanxi, Shaanxi, Gansu, Ningxia and Xinjiang provinces.

The suitability map and the land use map were crossed and the extent of each suitability level per land use class was calculated (Table 8). The result identified $245,509 \mathrm{~km}^{2}$ with very high suitability level and $310,723 \mathrm{~km}^{2}$ with high suitability level in Dryland, these areas which totaled $556,232 \mathrm{~km}^{2}$ can be considered as the best areas for naked oat cultivation. 


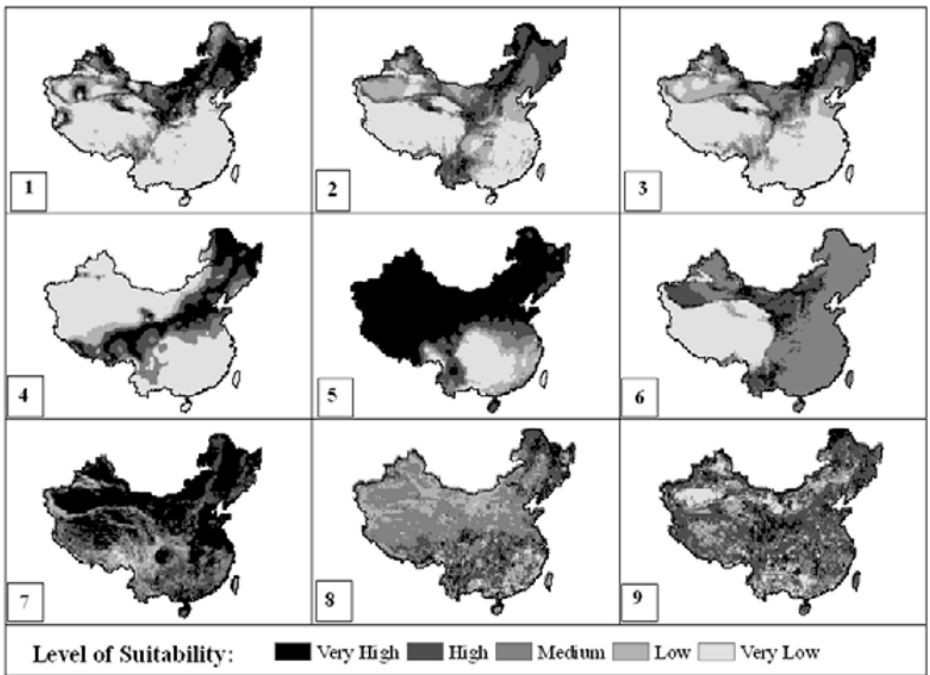

Fig.3: factor maps for naked oat, including suitability levels for each factor. 1= Accumulated temperature, $2=$ Maximum temperature, $3=$ minimum temperature, $4=$ Precipitation, $5=$ Sunlight duration, $6=$ Elevation, $7=$ slope, $8=$ Soil $\mathrm{pH}, 9=$ Soil texture class.

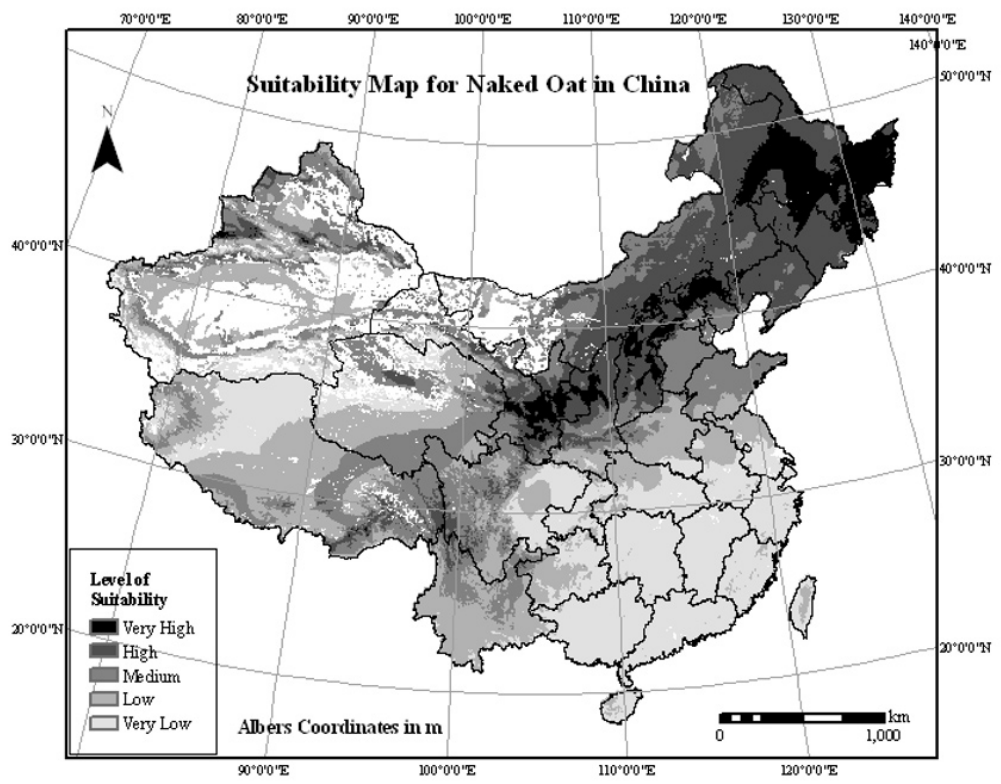

Fig.4: Suitability map for naked oat in China. 
Table 8. Result of crossing the suitability map for naked oat and land use map.

\begin{tabular}{llllll}
\hline \multirow{2}{*}{ Land use } & \multicolumn{5}{c}{ Suitability level } \\
\cline { 2 - 6 } & Very high & High & Medium & Low & Very low \\
\hline Pf & $12993^{\text {a }}$ & 21067 & 15156 & 81991 & 336033 \\
$\mathrm{Dl}$ & 245509 & 310723 & 338309 & 319747 & 214620 \\
$\mathrm{Fl}$ & 135534 & 434264 & 202782 & 240968 & 415819 \\
$\mathrm{Sh}$ & 28152 & 60325 & 67241 & 103576 & 118773 \\
$\mathrm{Sp}$ & 18348 & 63315 & 53685 & 107614 & 297925 \\
$\mathrm{Hg}$ & 60293 & 278848 & 405556 & 389848 & 112519 \\
$\mathrm{Mg}$ & 45193 & 254621 & 339814 & 355209 & 195800 \\
$\mathrm{Lg}$ & 17802 & 151231 & 269084 & 159064 & 122605 \\
$\mathrm{Sa}$ & 2057 & 25258 & 36966 & 39894 & 2688 \\
$\mathrm{Ml}$ & 16185 & 39631 & 11952 & 5086 & 652 \\
$\mathrm{Bl}$ & 7 & 6285 & 54738 & 15819 & 1839 \\
\hline
\end{tabular}

${ }^{a}$ Units are in square kilometers $\left(\mathrm{km}^{2}\right)$.

According to Ministry of Agriculture of the PRC (www.agri.gov.cn, 2005), the area cultivated with naked oat in China was approximately $2,800 \mathrm{~km}^{2}$, and most of the naked oat production areas were located in Dryland. However, our results showed $556,232 \mathrm{~km}^{2}$ considered as very high and high suitability areas for that crop in Dryland. In China, many oat production areas were located in Saline-alkaline land, for example, oats were planted in Baicheng in Jinlin province for the amelioration of the Saline-alkaline soil. Our result also identified $27,315 \mathrm{~km}^{2}$ as suitable areas for naked oat in Saline-alkaline land (Table 8).

After overlaying the results with province and county boundaries, suitability maps for naked oat in each province and each county were obtained. 779 counties in 19 provinces were identified as potential areas for planting naked oat, and their areas were calculated. Table 9 showed the suitable areas per land use type for each province, according to this result, Heilongjiang province has the largest suitable area for naked oat located in Dry land, Neimenggu, Jilin and Gansu province followed.

Table 9. Suitable areas for naked oat in each province, take Gansu, Heilongjiang, Neimenggu and Xinjiang province for example.

\begin{tabular}{lccccccccccc}
\hline \multirow{2}{*}{ Province } & \multicolumn{10}{c}{ Land use } \\
\cline { 2 - 12 } & Pf & Dl & Fl & Sh & Sp & Hg & Mg & Lg & Sa & Ml & Bl \\
\hline Gansu & 7 & 63532 & 16898 & 2125 & 3372 & 13780 & 19387 & 33504 & 163 & 114 & 1042 \\
Heilongjiang & 11045 & 144930 & 167318 & 8792 & 30122 & 38251 & 6496 & 2453 & 2629 & 23660 & 10 \\
Jilin & 8792 & 71261 & 72362 & 1824 & 8747 & 5882 & 3482 & 1220 & 7321 & 3953 & 104 \\
Neimenggu & 657 & 89649 & 123564 & 33928 & 6931 & 202388 & 128404 & 46023 & 8621 & 25363 & 1014 \\
Xinjiang & 26 & 8057 & 2600 & 933 & 787 & 12681 & 11002 & 50111 & 67 & 71 & 1424 \\
\hline
\end{tabular}




\section{DISCUSSION}

In this research the spatial data input, extraction, analysis and visualization functions of GIS were used to establish the national spatial database of climate, topography and soil. The correction of interpolated temperature maps by elevation could improve the accuracy of our result. These could be useful for other researchers to interpolate different climate factors in China. MCE procedure in this research was useful to evaluate the suitable areas for certain crops. In this MCE, the factors were selected based on agronomic knowledge of local experts and reviews of existing literature. Factor maps should be independent and the expert opinion was important for the definition of suitability level. Pair-wise comparison matrixes in the context of Analytical Hierarchy Process were made to obtain the weights and confirmed to be a useful approach in the decision-making process. Crossing of identified suitability maps with the land use information was important. Land use information was used not only for the elimination of unsuitable land use types, but also for constraining the result in the suitable land use types and minimizing the conflicts over land use. The introduction of administrative boundaries in this research was a useful approach that allowed us to present our results at national, provincial and county scales. This three-scale result presentation can provide general alternatives to agricultural land management of specific crops and varieties, being useful to different decision-makers such as local farmers, local government and the central government.

Furthermore, the feedback process of checking the results by local agronomic experts was involved, because results could be adjusted in light of their experience.

The identified suitable area for common oat and naked oat showed a zonal trend from southwest to northeast of China, this corresponds with the actual distribution of existing oat plantation sites. Besides, we found that the suitable area for common oat and naked oat is roughly consistent with the distribution of farming-pastoral ecotone in northern China (CAAS, 1984; Zhao et al., 2002). This result has demonstrated common oat and naked oat as the appropriate crops for agricultural production as well as for the Grainfor-Green process in the semi-arid regions of China.

However, the identified variety-suitable areas were proposed at a theoretical maximum, the microclimate and microtopography of the specific areas should be considered in the actual production. Decision-making process to select adequate crop patterns could be based on other issues such as: production supports (by local and federal governments), marketing, technological level, economic evaluation, in addition to local cultural traditions, which are highly important also. 


\section{CONCLUSIONS}

In this research, we applied the MCE approach to identify suitable areas for common oat with forage purpose and naked oat with grain purpose within a GIS environment. The results confirmed that the methodology used was adequate to construct and integrate spatial databases of climate, soil, topography and land use. The interpolated factor maps of temperature, precipitation, sunlight duration, elevation, slope, soil $\mathrm{pH}$, soil texture class and land use information were crucial in the identification of suitable areas for oat-crop production. The results were presented at national, provincial and county scales. The involvement of local crop expert opinion allowed us to generate reasonable delineating conditions and to obtain reliable and consistent results. Expert system based on the research results will be constructed and connected with the internet to facilitate the work of decision-makers and farmers.

\section{ACKNOWLEDGEMENTS}

This work is financial supported by the ISTCP for National Skeletal System for Agricultural Project Crops Mapping in China (2006DFA31070). We thank Ms. Julia Vedom, Mr. Fu Xiaofeng, Mr. Liu Yanming and Dr. Ye Jiansheng for their help during the research and the writing process.

\section{REFERENCES}

Ahamed T.R. N, Rao K. Gopal, Murthy J.S.R, 2000. GIS-based fuzzy membership model for crop-land suitability analysis. Agricultural Systems 63 (2000) 75-95

Carver, S.J., 1991. Integrating multi-criteria evaluation with geographical information systems. International Journal of Geographical Information System 5 (1991) 321-339.

Ceballos-Silva A, López-Blanco J, 2003. Delineation of suitable areas for crops using a Multi-Criteria Evaluation approach and land use/cover mapping: a case study in Central Mexico. Agricultural Systems. 77 (2003) 117-136.

Chinese Academy of Medical Sciences (CAMS), 1991. Food nutritional component. People's medical publishing house.5-18 (in Chinese).

Corbett, J.H., 1996. Dynamic crop environment classification using interpolated climate surfaces. In:Goodchild, M.F., Steyaert, T.L., Parks, O.B. (Eds.), GIS and Environmental Modeling: Progress Research Issues. GIS World Book, Fort Collins, pp. 117-122.

Dong Guanshui, Zhu Jiachang,1994. Meteorological elements of dryfarming naked oats and zones suitable for Cultivating. Meteorological Monthly.20(1994)47-50 (In Chinese)。

Du Jinglong, Chen Dechao,Wang Zhouhua ,2005. Construction and application of a variable fertilizer model based on GIS. Soils and Fertiizers. 02 (2005)17-20 (In Chinese).

Gao Yanfang, 2000. Application of GIS in evaluation of suitable areas for crops. Computing techniques for geophysical and geochemical exploration.3(2000) 257-261(In Chinese). 
Hou Xiangyang, Shi Jianzhong, 2003.Forage in west China Chemical Industry Press.6-10.

Heywood, I., Oliver, J., Tomlinson, S., 1995. Building an exploratory multi-criteria modeling environment for spatial decision support. In: Fisher, P. (Ed.), Innovations of GIS 2. Taylor and Francis, Leicester,UK, pp. 127-136.

Institute of Crop Germplasm Resources in Chinese Academy of Agric Sci(CAAS), 1996. Resource Catalog of oat varieties in China. Agricultural Press.1-79

Joerin, F., The' riault, M., Musy, A., 2001. Using GIS and outranking multicriteria analysis for land-use suitability assessment. International Journal of Geographical Information Science 10 (8), 321-339.

Li Jun, You Songcai, Huang Jingfeng, 2006. Spatial interpolation method and spatial distribution characteristics of monthly mean temperature in China during 1961-2000. Ecology and Environment. 15(1),109-114 (in Chinese)

Malczewski, J.A., 1996. GIS-based approach to multiple criteria group decision-making. International Journal of Geographical Information Science 10 (8), 321-339.

Pereira J.M.C., Duckstein L., 1993. A multiple criteria decision-making approach to GISbased land suitability evaluation. International Journal of Geographical Information Science 7 (5), 407-424.

Qiu Bingwen, Chi Tianhe, Wang Qinmin. Fruit tree suitability assessment using GIS and multi-criteria evaluation. Transact ions of the CSAE.21(2005) 96-100

Wang Bo,Song Fengbin,2006.Physiological responses and adaptive capacity of oats to salinealkali stress. Ecology and Environment.15 (2006) 625-629 (in Chinese)

Write Group of"Planting Division in China" of China Academy of Agriculture Science, 1984. Planting Division in China [M] . Beijing :Agriculture Press

Xiao-gang Li, Feng-min Li, Bhupinderpal-Singh, Zed Rengel, Zheng-yan Zhan, 2007. Soil management changes organic carbon pools in alpine pastureland soils. Soil \& Tillage Research 93 (2007) 186-196.

Xu Changlin,2003. Study on techniques of oat cultivation and production in the alpine region.

Pratacultural Science 20 (2003) 21-24 (In Chinese).

Zhang Xinyu, Chen Lidong, Li QIxin, Ma Yan, Fu Bojie, 2006. Effects of agricultural landuse on soil nutrients and the vertical distributions in traditional cultivated region, northern China. Journal of Agro-Environment Science. 25(2006) 377-381 (In Chinese).

Zhang Jianping, 2006. Study on naked oats nutrition components and functions. Food and Fermentation Industries. 11(2006) 128-130 (in Chinese).

Zheng Kekuan, Han Bin,Yu Haifeng, Zhang Quanzhai,2002.Ecnomical characters and usage of new variety of naked oat. Journal of Inner Mongola Institute of Agriculture and Animal Husbandry. 23(2002)61-65(In Chinese).

Zhao Halin, Zhao Xueyong, Zhang Tonghui, Zhou ruilian,2002.Boundary line on agropasture zigzag zone in north China and it's problems on eco-environment. Advance in earth sciences. 17 (2002)739-747 (In Chinese). 